Roy Abraham Kallivayalit',Arun Enara ${ }^{2}$

\title{
Undergraduate Education in Psychiatry in India
}

\author{
'Professor \& Head, Dept of Psychiatry, Pushpagiri Institute of Medical Sciences, Thiruvalla, Kerala- 689 101, India \\ ${ }^{2}$ Former Senior Resident, National Institute of Mental Health \& Neuro Sciences, Bangalore, 560029, India
}

*email: roykalliagmail.com

DOI: 10.2478/gp-2020-0006

Received: 16 September 2019; Accepted: 20 February 2020

\begin{abstract}
Medical education curricula, from around the world, have often neglected psychiatry as a subject of importance in undergraduate medical training.

In India, the scenario has not been different from the rest of the world. The National Mental Health Survey done in India, recently, estimates a treatment gap of around 80-85\% for various mental illnesses. This provides a strong case to strengthen the undergraduate psychiatry curricula since it would help tackle the treatment gap of common mental disorders in the community.

Further, a strong educational foundation with meaningful inclusion of mental health and well-being, will also make the trainee aware of their own mental well-being and better help seeking behaviour in the medical student. In this article, we look to review the evolution of undergraduate medical education in India.
\end{abstract}

\section{Keywords}

Psychiatry, medical curriculum, psychiatry training, India

\section{INTRODUCTION}

'The highest form of ignorance is to reject something you know nothing about.'

Wayne W. Dyer

Mental health is defined as a state of well-being in which every individual realizes his or her own potential, can cope with the normal stresses of life, can work productively and fruitfully, and is able to make a contribution to her or his community ('WHO | Promoting Mental Health; concepts, emerging evidence and practice', n.d.)). WHO places mental health on a par with physical and social well-being, in its definition of health.

In the undergraduate Bachelor of Medicine and Bachelor of Surgery (MBBS) curriculum in India, according to the national curriculum requirement, psychiatry is allocated 20 hours of lectures, optional clinical posting before the final professional examination, and 2 weeks of clinical posting during internship. There is, however, a vast variation regarding the duration of posting and quantum of teaching from one medical college to another (Trivedi, 1998).
According to the National Mental Health Survey (NMHS) of 2015-2016 ('Gururaj G, Varghese M, Benegal V, Rao GN, Pathak K, Singh LK, Mehta RY, Ram D, Shibukumar TM, Kokane A, Lenin Singh RK, Chavan BS, Sharma P, Ramasubramanian C, Dalal PK, Saha PK, Deuri SP, Giri AK, Kavishvar AB, Sinha VK, Thavody J, Chatterji R, Akoijam BS, Das S, Kashyap A, Ragavan VS, Singh SK, Misra R and NMHS collaborators group. National Mental Health Survey of India, 2015-16: Prevalence, patterns and outcomes. Bengaluru, National Institute of Mental Health and Neuro Sciences, NIMHANS Publication No. 129, 2016.', n.d.), the overall weighted lifetime prevalence for any mental illness was $13.7 \%$ and the current prevalence was $10.6 \%$. Another large multi-country survey supported by the WHO showed that $35-50 \%$ of the serious cases in developed countries and $76-85 \%$ in the less-developed countries had received no treatment in the previous 12 months (Demyttenaere et al., 2004). Consistent with the previous studies from India, the findings from the NMHS reported an overall treatment gap of $83 \%$ for any mental health problem. The NMHS also reported that 3 out of the 4 persons with a mental disorder have significant disability. Primary care practitioners often fail to recognize psychiatric disorders in patients with physical 
illness ('Goldberg D. Reasons for misdiagnosis. In: Sartorius N, de Girolamo G, Goldberg D, Costa e Silva JA, Lecrubier $\mathrm{Y}$, Wittchen HU, editors. Psychological disorders in general medical settings. Göttingen: Hogrefe and Hubert; 1990. pp. 139凶45.', n.d.).

Similarly, half the psychiatric morbidity is not detected by the treating team in medical and surgical wards (Maguire et al., 1974). Factors related to mental illness can interfere with the treatment of other illnesses and frequently co-occur with cardiovascular, diabetes, cancer, and other non-communicable diseases (Sorel and Satcher, 2011). There is also evidence suggesting that the current psychiatry training has multiple lacunae affecting the undergraduates' knowledge of psychiatry (Chawla et al., 2012) .

The essential qualities for a doctor include skills in communication and the ability to form empathy. These are refined while learning psychiatry. The ability to encourage a positive mental health as well as the acquisition of counselling skills are necessary for all doctors, to assist with reducing stress and coping with chronic physical health problems (Manohari et al., 2013; Kelly et al., 1991). These aforementioned insights contribute towards motivating for strengthening the undergraduate psychiatry training in India.

\section{EVOLUTION OF UNDERGRADUATE PSYCHIATRY TRAINING IN INDIA}

Articles by Kallivayalil (2012) and Kumar et al. (2018) provide insight into the evolution of undergraduate psychiatry training in India.

- At the time of Indian Independence, the Bhore Committee, 1946, emphasized the need for training in the social aspects of medicine to boost India's meagre mental health resources (19 hospitals with 10,181 beds and a few general hospital psychiatric units). It also recommended setting up of psychiatry departments in every general hospital to review and enhance the existing curriculum and training in Psychiatry for medical undergraduates.

- In 1965, the first seminar on "undergraduate teaching in psychiatry" was held at the Central Institute of Psychiatry in Ranchi where a task force was constituted. Many deficiencies were recognized and reforms were proposed.

- The Srivastava Committee in 1970 emphasized that medical education should be imparted in a manner in accordance with national needs and preferences. They recommended the constitution of a medical education committee to implement the changes.
- In 1982, the National Mental Health Program (NMHP) findings noted that the extent and nature of mental health teaching to medical undergraduates is unacceptable and inadequate. It emphasized the prospective use of these future clinicians as a channel for a better mental health service system.

- In 1983, a National workshop on 'undergraduate medical education in mental health' was conducted in JIPMER (Jawaharlal Institute of Postgraduate Medical Education), Pondicherry.

- The Bajaj Committee in 1986, recommended updating course content and using innovative teaching methods. It also suggested faculty expansion and transparent funding.

- A workshop on teachers' training was held in 1989 at NIMHANS (National Institute of Mental Health and Neuro Science). Ways to improve undergraduate teaching were identified. A recommendation to MCI (Medical Council of India) in making psychiatry a fully-fledged subject was also made.

- A national workshop on 'Social and Behavioural Sciences in Mental Health' was conducted in 1994 at AIIMS (All India Institute of Medical Sciences), New Delhi. The workshop identified a lack of orientation towards behavioural sciences to be the main reason for the lack of interest in psychiatry in undergraduates.

- In 2004, the Majumdar Committee, which was a Government commissioned report, emphasized leadership and political commitment to achieve evidence based medical education.

- The Undergraduate psychiatry task force reviewed undergraduate training and recommended objectives for undergraduate teaching in 2010. The task force emphasized training to deliver basic mental health facilities at primary care level.

- In 2011, MCI incorporated the following changes to the psychiatric curriculum at undergraduate level: 1 . The teaching hours increased from 20 to 40 hours; 2. The clinical posting increased from 2 weeks to 4 weeks; 3 . The doubling up of the marks to 20 in the theory exam paper for medicine and compulsory answering of the questions related to Psychiatry; 4. Internal assessment to be made compulsory for final examination; 5. Psychiatry posting in the internship period was made obligatory, instead of optional; 6. The training in Psychiatry to be imparted in an integrated manner, particularly with Community Medicine.

- In 2011, MCI and Ministry of Health and Family Welfare officials met multiple times with a delegation led by $\mathrm{Dr}$ Roy Abraham Kallivayalil, who was the then IPS (Indian Psychiatric Society) President, to consider making psychiatry a separate subject in undergraduate training. 


\section{UNDERGRADUATE PSYCHIATRY TRAINING IN THE WEST AND REST OF ASIA}

In the USA (United States of America), Behavioural Sciences are taught in the first year of undergraduate studies. During the first 2 years, there are about 60 hours of teaching in various psychosocial areas. In the third year, 30 hours are devoted to practical teaching of Psychiatry. In the fourth year, there is a full-time posting of 8 weeks of Psychiatry clerkship compared to 8 weeks each allotted for Obstetrics and Paediatrics, and 12 weeks for both Medicine and Surgery (Kallivayalil, 2012).

In Denmark, the teaching of mental disorders started in 1902 and was well established by 1912. During the fifties, it acquired the status of a major clinical subject, rising to the third place after Surgery and Medicine and ahead of Paediatrics and Obstetrics and Gynaecology. Currently, there are approximately 240 hours of Psychiatry teaching in a 6-year course, comprising about $7 \%$ of the total time. It is a major clinical discipline with a qualifying examination at the end of the course (Kallivayalil, 2012).

In Britain, Psychiatry established its place in medical education in the nineteen forties. However, it went through major changes in the nineteen seventies following the General Medical Council's recommendations in 1967 regarding medical education, which re-emphasized the importance of Behavioural Sciences and Psychiatry in medical teaching and practice. Currently, 80 hours are devoted to the behavioural science course during the basic medical science teaching. During the clinical course, students first learn interview skills and psychiatry history taking once a day during the 36 weeks and then attend a full-time Psychiatry clerkship for 3 months. This is usually followed by a university examination as in other subjects (Kallivayalil, 2012).

In Malaysia, psychiatry undergraduate training involves 100 hours of total teaching. The psychiatric aspects of diseases are taught starting in the first year of training. This is followed by separate courses in General and Community Psychiatry. The students are required to submit reports of 5 detailed clinical cases with discussion on management. The students will also have to undergo a formal assessment at the end of clinical postings (Kumar et al., 2018).

In Ethiopia, there is a mandated 20 hours of teaching in behavioural sciences in the first two years. An 8 weeks' full time posting in psychiatry was reduced to 6 weeks owing to shortage of staff. Psychiatry remains a major clinical subject and is examined in the final year (Kumar et al., 2018).
In Pakistan, psychiatry clinical clerkships range from 3-6 weeks (Gadit, 2007). Sri Lanka, Nepal and Malaysia have a greater duration of psychiatric clinical rotation than earmarked for the Indian medical colleges.

Thus, psychiatric training and exposure have received lesser attention in India as compared to other countries, and as compared to some of the other disciplines in India (Sagar, 2016.). Both Sri Lanka and Nepal give prominence to Psychiatry and medical students need to pass an examination in Psychiatry to qualify for medical degree (Kumar et al., 2018)

\section{CURRENT STATUS OF UNDERGRADUATE PSYCHIATRY TRAINING IN INDIA}

The undergraduate psychiatry training in India continues to be a neglected area when comparing the global standards and the curriculum implemented in the rest of the world. The recommendations from the national and international bodies have been ignored and the training of undergraduates continues to suffer. The changes suggested by the Medical Council of India (MCI) in 2011, are not yet implemented except the 2 weeks' compulsory postings during internship (Kallivayalil, 2012). The MCI's decision on compulsory internship for MBBS graduates is a significant step forward.

Although an impressive list of recommendations have been made by the MCI - like increasing the teaching hours allocated for psychiatry, making psychiatry posting mandatory during internship, being taught in an integrated manner with community medicine, increasing the marks allocated during final assessment, and internal assessment being made mandatory for final assessment - implementation remains a challenge (Kallivayalil, 2012).

The recommendation of the Ministry of Health and Family Welfare (MoHFW) to MCI for making psychiatry a subject for examination has not been implemented, even after many years since the recommendation. Psychiatrists are still not involved in the setting of theory question papers, evaluation of papers and also internal assessments. There is a lack of political and administrative motivation to change the reality on the ground.

\section{PSYCHIATRY AS A SEPARATE UNDERGRADUATE SUBJECT - THE NEED}

Mental disorders account for an enormous global burden of disease that is largely underestimated and underappreciated. In a given year, about $30 \%$ of the population worldwide is affected by a mental disorder and over two-thirds of those affected do 
not receive the care they need (Lancet Global Mental Health Group et al., 2007).

The projected burden of mental health disorders is expected to reach $15 \%$ of all disability adjusted life years by the year 2020, where common mental disorders (depression, anxiety and substance-related disorders including alcohol) will disable more people than complications arising from AIDS, heart disease, traffic accidents and wars combined (Kallivayalil, n.d.). Almost one-third (28\%) of disability-adjusted life-years in 2005 were attributed to neuropsychiatric disorders (Murray et al., 1996)

There is a shortage of psychiatrists in India. Currently, the country produces 1 psychiatrist for 2.5 million population/year (Kavoor and Mitra, 2015). This concern could be circumvented if the primary physicians are trained to tackle many of the mental health problems and only selective cases need be seen by a specialist. Much of the caseload of psychiatric disorders can be handled by the primary care physicians, and only selected cases need referral to a specialist. The increase in hours of clinical training in psychiatry will in turn increase the knowledge of psychiatric disorders and also improve the attitude towards patients and mental illness (Sagar, n.d.).

It has been seen that clinical posting in psychiatry has been associated with an increase in knowledge about psychiatric disorders and improved attitude toward patients with mental illnesses (Gulati et al., 2014).

There is also a need to reorient the outlook of medical students towards mental illness, mental well-being and psychiatry as a choice of specialisation. The overall status of psychiatry as a discipline is low; some studies also report positive changes in attitudes, either over the course of time or after completion of psychiatric training during medical school. The improvement in attitude seems to be transient. Despite positive attitudes, the proportion of medical students indicating they would choose psychiatry as a career is often low (Sartorius et al., 2010). Psychiatry is considered as one of the least important subjects during the medical training often engulfed by the more demanding and authoritative subjects of medicine, surgery and obstetrics (Reddy, 2007).

Psychiatry ends up remaining a small part of the general medicine course. The only active effort from the student is in terms of memorising a few short notes that may come as a part of their final year MBBS medicine theory paper. According to the current medical interns, the psychiatry ward remains obscure and a place to relax after the hectic postings of labour rooms and emergency/casualties. More disturbing is the lack of even basic teaching infrastructure in psychiatry in many undergraduate medical colleges, and of teachers in psychiatry who are 'inspiring' enough (Reddy, 2007). This in turn generates a large number of trained medical graduates lacking grossly in psychiatric interviewing skills, their abilities to empathize and understand psychopathology. This often leads to few of them taking up psychiatry as a specialisation for post-graduation (Kavoor and Mitra, 2015).

Psychiatry is often thought of as a not medical or scientific enough speciality by the students (Sartorius et al., 2010.; Abramowitz and Bentov-Gofrit, 2005; Furnham, 1986; Malhi et al., 2002). They often view psychiatry as one of low prestige and low precision, and think that most patients can be managed by non-physicians (Yager, 2011). Medical students often viewed psychiatric treatment as ineffective (Sartorius et al., 2010; Calvert et al., 1999) and considered psychiatry to be 'too slow moving' (Brockington and Mumford, 2002)

The lack of adequate financial remuneration in comparison to other specialities and the lack of job opportunities also adds to the vicious cycle, thereby impacting the student's choice of taking up psychiatry as a subject for post-graduation (Manohari et al., 2013). A further influential aspect is the impact of students' families on their attitudes and their decision to aim for a career in psychiatry. Stereotypes, such as specializing in psychiatry being 'wasted time', are widespread among the families of medical students (Compton et al., 2008). Making psychiatry a separate speciality rotation in undergraduate training will improve their exposure to psychiatry by allocating more hours for teaching and training. This would go a long way in tackling many of the misconceptions students hold today regarding this speciality.

There has been an increase in the suicide rates among medical residents all over the world (Wible, 2018). In a cross-sectional study based on an online survey done in PGIMER, Chandigarh, $30.1 \%$ of participants were found to have depression and $16.7 \%$ of participants reported suicidal ideation. About two-thirds of the sample experienced moderate level of stress (67.2\%) and another $13 \%$ of participants reported high level of stress. More than $90 \%$ of the participants reported some level of burnout. The study suggested that a significantly higher proportion of doctors in an Indian setting experience stress, depression, and burnout. Unmet mental health needs of medical students and physicians are high in India. The current training and exposure is inadequate to equip the doctors in recognising and reaching out for help if burn out ensues. There is a need to orient undergraduate medical students to issues such as burnout 
and the stress involved during training and while practising this profession (Menon et al., 2015). Orienting the resident to recognize depressive symptoms in themselves and their colleagues can go a long way in improving their perceptions (Kumar et al., 2018). Training in the undergraduate medical curriculum on enabling the residents to seek help when needed should be one of the objectives of postings in psychiatry.

The ability to form a good relationship with a patient, to assess the mental state and to impart distressing information should be at the heart of any medical speciality (Murthy and Khandelwal, 2007). Encouraging positive mental health and counselling skills to reduce stress and cope with chronic physical health problems are necessary for all doctors to master. There is also increasing need for improved skills by medical graduates in the psychosocial aspects of medical care (Manohari et al., 2013). In the age of increasing violence towards the medical fraternity (Ghosh, 2018), being good communicators, understanding the distressing situations and handling them professionally with empathy will go a long way in tackling the violence. An effective psychiatry training will be at the heart of creating such medical professionals.

\section{WORLD PSYCHIATRIC ASSOCIATION RECOMMENDATIONS TO IMPROVE UNDERGRADUATE PSYCHIATRY TRAINING}

In 1998, the World Psychiatric association (WPA), along with the World Federation of Medical Education (WFME) ('World Psychiatric Association. WPA core curriculum in psychiatry for medical students. New York: World Psychiatric Association and World Federation for Medical Education; 1998., ' n.d.) through a core curriculum committee, developed detailed guidelines for the 'Core Curriculum in Psychiatry for Medical Students.'

The main recommendation that Psychiatry should occupy a major part in the medical curriculum is now generally agreed. There are three reasons for this agreement. First, the general approach of Psychiatry, which stresses that the unity of body and mind is important in the whole of medical practice. Secondly, skills that are learned in Psychiatry are important for all doctors: for example, the ability to form a good relationship with a patient, to assess the mental state, and to convey distressing information. Thirdly, psychiatric problems are common among patients seen by doctors working in all branches of medicine. For example, it is known that among outpatients attending specialist clinics, about $15 \%$ of those given a diagnosis have an associated psychiatric disorder and an average of $20-30 \%$ of those given no medical diagnosis have a psychiatric disorder. Psychiatric disorders are even more frequent among patients attending general practice. Therefore, all future doctors must know about these psychiatric problems, not only because they are common but also because their management involves much medical time and resources and not managing them appropriately gives rise to many serious incidents (Kallivayalil, 2012; Murthy and Khandelwal, 2007).

\section{INDIAN PSYCHIATRIC SOCIETY (IPS) RECOMMENDATIONS FOR UNDERGRADUATE TRAINING}

In an editorial in the Indian Journal of Psychiatry, (Trivedi, 1998) said, 'The basic purpose of teaching and training at undergraduate level is to prepare medical graduates to serve better at primary health care level. The patients with physical illness have concomitant emotional problems requiring professional handling; therefore, teaching of Psychiatry at undergraduate level becomes even more relevant and essential.'

The IPS in 2010 ('Indian Psychiatric Society: Recommendations for Under-graduate (MBBS) syllabus in Psychiatry. Report prepared by the Psychiatric Education Committee of Indian Psychiatric Society chaired by RC Jiloha. 2010.', n.d.) submitted a document to the MCI, prepared by its Psychiatric Education Committee. It stated that a medical student on graduation should be able to deliver mental health services at primary care level and listed the following main objectives:

1. Able to identify signs and symptoms of common psychiatric illnesses

2. Able to identify developmental delays including cognitive delays

3. Able to understand the nature and development of normal human behaviour

4. Able to appreciate the interplay between psychological and physical factors in medical presentations

5. Aware of common psychopharmacological interventions in clinical practice of psychiatry

6. Able to apply basic counselling skills and comfort in discussing common psychiatric issues with the patient or the relative

7. Aware of statutory and educational provisions with regard to psychiatric illnesses and disability

8. Able to develop helpful and humane attitude toward psychological, psychiatric and behavioural difficulties

9. Able to deliver mental health services at primary care level

A detailed course content involving what the student is expected to gain at the end of undergraduate psychiatry training was also 
listed in the recommendations. Making psychiatry a separate subject in the undergraduate medical curriculum would ensure that the above-mentioned objectives are met and that primary care physicians are strengthened to tackle the common mental health problems.

\section{CONCLUSION - THE ROAD AHEAD}

There is a need to investigate new ideas and strategies regarding the undergraduate psychiatry teaching curriculum in India. It is also time to give psychiatry its due in shaping the undergraduates of today into the basic mental health providers of tomorrow (Trivedi, 1998). The present era presents to us a lot of opportunities. The favourable MCI ruling that every medical college should have a psychiatry department ensures basic exposure and orientation of undergraduates towards psychiatry (Kumar et al., 2018). Although not enough, this should be seen as an opportunity to strengthen the basic doctors of tomorrow to tackle mental health issues in the primary care. The establishment of numerous deemed universities in India can be an opportunity to teach psychiatry to the undergraduate student, as the University Grants Commission has given them enough flexibility to design their curriculum, resulting in some of them accommodating psychiatry as a mandatory part of their examination system (Kishor et al., 2016). Many successful models of training including the AIIMS model (Sood and Sharan, 2012) as a step in the right direction.

Primary health care is the cornerstone of healthcare delivery, especially in the developing world ('Issac MK, ChandrasekarCR, Srinivasa Murthy R. Mental health care by primary care doctors. Bangalore: National Institute of Mental Health and Neurosciences; 1994., n.d.). Hence, medical curricula at both the undergraduate and postgraduate levels should adapt and evolve to produce professionals with a person-centred approach. This requires a change in policy on the selection of students to medical school and the content of medical curricula and examinations (Kallivayalil and Punnoose, 2011).

Psychiatry is advancing as a field and it is important to capture young imagination. A comprehensive yet brief course curriculum, enthusiastic faculty, and implementation of quality evaluations could all improve student engagement and promote psychiatry to where it deserves to be (Kavoor and Mitra, 2015).

The task before us is to impart knowledge and arouse interest, as well as to remove the stigma against psychiatry and psychiatrists (Manohari et al., 2013).

The rest of the world has recognised the importance of strengthening undergraduate and postgraduate training in psychiatry. The 'Choose Psychiatry' campaign by the Royal College of Psychiatrists is very commendable and another step in the right direction ('Choose Psychiatry', n.d.). To quote Stephen Fry during the 'Choose Psychiatry' campaign, 'Physical health is important but nowhere near as exciting as the science of cognition and consciousness. The brightest and the best minds must join the fight against mental illness.'

\section{SOURCE OF FUNDING}

$\mathrm{Nil}$

\section{CONFLICT OF INTEREST}

Nil

\section{REFERENCES}

Abramowitz, M.Z., Bentov-Gofrit, D., 2005. The attitudes of Israeli medical students toward residency in psychiatry. Acad Psychiatry 29, 92-95. https://doi.org/10.1176/appi.ap.29.1.92

Brockington, I., Mumford, D., 2002. Recruitment into psychiatry. Br J Psychiatry 180, 307-312.

Calvert, S.H., Sharpe, M., Power, M., Lawrie, S.M., 1999. Does undergraduate education have an effect on Edinburgh medical students' attitudes to psychiatry and psychiatric patients? J. Nerv. Ment. Dis. 187, 757-761.

Chawla, J.M., Balhara, Y.P.S., Sagar, R., Shivaprakash, null, 2012. Undergraduate medical students' attitude toward psychiatry: a cross-sectional study. Indian J Psychiatry 54, 37-40. https://doi. org/10.4103/0019-5545.94643

Choose Psychiatry [WWW Document], n.d. . RC PSYCH ROYAL COLLEGE OF PSYCHIATRISTS. URL https://www.rcpsych.ac.uk/ become-a-psychiatrist/choose-psychiatry laccessed 2.18.20).

Compton, M.T., Frank, E., Elon, L., Carrera, J., 2008. Changes in U.S. medical students' specialty interests over the course of medical school. J Gen Intern Med 23, 1095-1100. https://doi. org/10.1007/s11606-008-0579-z

Demyttenaere, K., Bruffaerts, R., Posada-Villa, J., Gasquet, I., Kovess, V., Lepine, J.P., Angermeyer, M.C., Bernert, S., de 
Girolamo, G., Morosini, P., Polidori, G., Kikkawa, T., Kawakami, N., Ono, Y., Takeshima, T., Uda, H., Karam, E.G., Fayyad, J.A., Karam, A.N., Mneimneh, Z.N., Medina-Mora, M.E., Borges, G., Lara, C., de Graaf, R., Ormel, J., Gureje, O., Shen, Y., Huang, Y., Zhang, M., Alonso, J., Haro, J.M., Vilagut, G., Bromet, E.J., Gluzman, S., Webb, C., Kessler, R.C., Merikangas, K.R., Anthony, J.C., Von Korff, M.R., Wang, P.S., Brugha, T.S., Aguilar-Gaxiola, S., Lee, S., Heeringa, S., Pennell, B.-E., Zaslavsky, A.M., Ustun, T.B., Chatterji, S., WHO World Mental Health Survey Consortium, 2004. Prevalence, severity, and unmet need for treatment of mental disorders in the World Health Organization World Mental Health Surveys. JAMA 291, 2581-2590. https://doi.org/10.1001/jama.291.21.2581

Furnham, A.F., 1986. Medical students' beliefs about nine different specialties. Br Med J (Clin Res Ed) 293, 1607-1610.

Gadit, A.A.M., 2007. Psychiatry in Pakistan: 1947-2006: a new balance sheet. J Pak Med Assoc 57, 453-463.

Ghosh, K., 2018. Violence against doctors: A wake-up call. Indian J Med Res 148, 130-133. https://doi.org/10.4103/ijmr.IJMR_1299_17

Goldberg D. Reasons for misdiagnosis. In: Sartorius N, de Girolamo G, Goldberg D, Costa e Silva JA, Lecrubier Y, Wittchen $\mathrm{HU}$, editors. Psychological disorders in general medical settings. Göttingen: Hogrefe and Hubert; 1990. pp. 139-45., n.d.

Gulati, P., Das, S., Chavan, B.S., 2014. Impact of psychiatry training on attitude of medical students toward mental illness and psychiatry. Indian J Psychiatry 56, 271-277. https://doi. org/10.4103/0019-5545.140640

Gururaj G, Varghese M, Benegal V, Rao GN, Pathak K, Singh LK, Mehta RY, Ram D, Shibukumar TM, Kokane A, Lenin Singh RK, Chavan BS, Sharma P, Ramasubramanian C, Dalal PK, Saha PK , Deuri SP, Giri AK, Kavishvar AB, Sinha VK, Thavody J, Chatterji R, Akoijam BS, Das S, Kashyap A, Ragavan VS, Singh SK, Misra $\mathrm{R}$ and NMHS collaborators group. National Mental Health Survey of India, 2015-16: Prevalence, patterns and outcomes. Bengaluru, National Institute of Mental Health and Neuro Sciences, NIMHANS Publication No. 129, 2016., n.d.

Indian Psychiatric Society: Recommendations for UnderDgraduate (MBBS) syllabus in Psychiatry. Report prepared by the Psychiatric Education Committee of Indian Psychiatric Society chaired by RC Jiloha. 2010., n.d.

Issac MK, ChandrasekarCR, Srinivasa Murthy R. Mental health care by primary care doctors. Bangalore: National Institute of Mental Health and Neurosciences; 1994., n.d.
Kallivayalil, n.d. Global mental health movement has helped in reducing the global burden of psychiatric disorders [WWW Document]. URL http://www.indjsp.org/article.asp?issn=09719962; year $=2016$; volume $=32$;issue $=3$; page $=257$; epage $=260$; aulast $=$ Kallivayalil laccessed 6.30.18).

Kallivayalil, R., 2012. The importance of psychiatry in undergraduate medical education in India. Indian Journal of Psychiatry 54, 208. https://doi.org/10.4103/0019-5545.102336

Kallivayalil, R.A., Punnoose, V.P., 2011. Person-centered medicine and primary healthcare: academic perspectives. International Journal of Person Centered Medicine 1, 433-434. https://doi. org/10.5750/ijpcm.v1i3.97

Kavoor, A.R., Mitra, S., 2015. Psychiatry at undergraduate level in India: What is needed? J Neurosci Rural Pract 6, 449-450. https:// doi.org/10.4103/0976-3147.158804

Kelly, B., Raphael, B., Byrne, G., 1991. The evaluation of teaching in undergraduate psychiatric education: students' attitudes to psychiatry and the evaluation of clinical competency. Med Teach 13, 77-87.

Kishor, M., Isaac, M., Ashok, M.V., Pandit, L.V., Rao, T.S., 2016. Undergraduate psychiatry training in India; past, present, and future looking for solutions within constraints!! Indian Journal of Psychiatry 58, 119. https://doi.org/10.4103/0019-5545.183794

Kumar, P., Jangid, P., Sethi, S., 2018. Undergraduate psychiatry in India: A SWOT analysis. Asian Journal of Psychiatry 33, 46-51. https://doi.org/10.1016/j.ajp.2018.02.018

Lancet Global Mental Health Group, Chisholm, D., Flisher, A.J., Lund, C., Patel, V., Saxena, S., Thornicroft, G., Tomlinson, M., 2007. Scale up services for mental disorders: a call for action. Lancet 370, 1241-1252. https://doi.org/10.1016/S0140-6736(07)61242-2

Maguire, G.P., Julier, D.L., Hawton, K.E., Bancroft, J.H., 1974. Psychiatric morbidity and referral on two general medical wards. Br Med J 1, 268-270.

Malhi, G.S., Parker, G.B., Parker, K., Kirkby, K.C., Boyce, P., Yellowlees, P., Hornabrook, C., Jones, K., 2002. Shrinking away from psychiatry? A survey of Australian medical students' interest in psychiatry. Aust N Z J Psychiatry 36, 416-423. https://doi. org/10.1046/j.1440-1614.2002.00991.x

Manohari, S.M., Johnson, P.R., Galgali, R.B., 2013. How to Teach Psychiatry to Medical Undergraduates in India?: A Model. Indian J Psychol Med 35, 23-28. https://doi.org/10.4103/0253-7176.112196 
Menon, V., Sarkar, S., Kumar, S., 2015. Barriers to healthcare seeking among medical students: a cross sectional study from South India. Postgrad Med J 91, 477-482. https://doi.org/10.1136/ postgradmedj-2015-133233

Murray, C.J., Lopez, A.D., Organization, W.H., 1996. The global burden of disease: a comprehensive assessment of mortality and disability from diseases, injuries, and risk factors in 1990 and projected to 2020: summary.

Murthy, R.S., Khandelwal, S., 2007. Undergraduate training in Psychiatry: World perspective. Indian J Psychiatry 49, 169-174. https://doi.org/10.4103/0019-5545.37316

Reddy, I.R., 2007. Undergraduate psychiatry education: Present scenario in India. Indian J Psychiatry 49, 157-158. https://doi. org/10.4103/0019-5545.37311

Sagar, n.d. Psychiatry as a separate subject in the undergraduate medical curriculum: The need re-emphasized [WWW Document]. URL http://www.jmhhb.org/article.asp?issn=0971-8990;year $=2016$; volume $=21$; issue $=2 ;$ spage $=88$; epage $=90$; aulast $=$ Sagar laccessed 6.27.18).

Sartorius, N., Gaebel, W., Cleveland, H.-R., Stuart, H., Akiyama, T., ArboledaDFlórez, J., Baumann, A.E., Gureje, O., Jorge, M.R., Kastrup, M., Suzuki, Y., Tasman, A., n.d. WPA guidance on how to combat stigmatization of psychiatry and psychiatrists. World Psychiatry 9, 131-144. https://doi.org/10.1002/j.2051-5545.2010. tb00296.x

Sood, M., Sharan, P., 2012. Undergraduate training in psychiatry at AlIMS: Integration with community medicine. Indian Journal of Psychiatry 54, 93. https://doi.org/10.4103/0019-5545.94659

Sorel, E., Satcher, D., 2011. The U.N.'s Unfortunate Exclusion. Psychiatric News. https://doi.org/10.1176/pn.46.19. psychnews_46_19_8_2

Trivedi, J.K., 1998. Importance of Undergraduate Psychiatric Training. Indian Journal of Psychiatry 40, 101.

WHO I Mental health: a state of well-being [WWW Document], n.d. WHO. URL http://www.who.int/features/factfiles/mental_health/ en/ laccessed 6.27.18).

WHO I Promoting Mental Health; concepts, emerging evidence and practice [WWW Document], n.d. . WHO. URL http://www.who.int/ mental_health/publications/promoting_mh_2005/en/ laccessed 2.18.20).
Wible, P., 2018. What I've learned from my tally of 757 doctor suicides. Washington Post.

World Psychiatric Association. WPA core curriculum in psychiatry for medical students. New York: World Psychiatric Association and World Federation for Medical Education; 1998., n.d.

Yager, J., 2011. The practice of psychiatry in the 21st century: challenges for psychiatric education. Acad Psychiatry 35, 283-292. https://doi.org/10.1176/appi.ap.35.5.283 